\title{
Increased D-amino acid oxidase expression in the bilateral hippocampal CA4 of schizophrenic patients: a post-mortem study
}

\author{
Gregor Habl · Mathias Zink · Georg Petroianu • Manfred Bauer • \\ Thomas Schneider-Axmann • Martina von Wilmsdorff • Peter Falkai • \\ Fritz A. Henn · Andrea Schmitt
}

Received: 27 May 2009/ Accepted: 4 September 2009/Published online: 13 October 2009

(C) The Author(s) 2009. This article is published with open access at Springerlink.com

\begin{abstract}
An important risk gene in schizophrenia is D-amino acid oxidase (DAAO). To establish if expression of DAAO is altered in cortical, hippocampal or thalamic regions of schizophrenia patients, we measured gene expression of DAAO in a post-mortem study of elderly patients with schizophrenia and non-affected controls in both hemispheres differentiating between gray and white matter. We compared cerebral post-mortem samples
\end{abstract}

G. Habl · M. Zink · F. A. Henn · A. Schmitt

Central Institute of Mental Health, P.O. Box 1221 20,

68072 Mannheim, Germany

G. Habl

Department of Radiation Oncology, University of Heidelberg, Im Neuenheimer Feld 400, 69120 Heidelberg, Germany

\section{G. Petroianu}

Department of Cellular Biology and Pharmacology, Florida International University, 11200 SW 8th Street, GL 495E, Miami, FL 33199, USA

Present Address:

F. A. Henn

Life Sciences, Brookhaven National Laboratory,

Bldg. 490, Upton, NY 11973-5000, USA

M. Bauer

Department of Neuropathology,

University of Leipzig, Liebigstr. 26, 04103 Leipzig, Germany

T. Schneider-Axmann · P. Falkai · A. Schmitt $(\bowtie)$

Department of Psychiatry, University of Goettingen,

Von-Siebold Str. 5, 37075 Goettingen, Germany

e-mail: aschmit@gwdg.de

M. von Wilmsdorff

Department of Psychiatry Rheinische Kliniken,

University of Duesseldorf, Bergische Landstr. 2,

40629 Duesseldorf, Germany (granular frontal cortex BA9, middle frontal cortex BA46, superior temporal cortex BA22, entorhinal cortex BA28, sensoric cortex BA1-3, hippocampus (CA4), mediodorsal nucleus of the thalamus) from 10 schizophrenia patients to 13 normal subjects investigating gene expression of DAAO in the gray and white matter of both hemispheres of the above-mentioned brain regions by in situ-hybridization. We found increased expression of DAAO-mRNA in the hippocampal CA4 of schizophrenic patients. Compared to the control group, both hemispheres of the hippocampus of schizophrenic patients showed an increased expression of $46 \%$ (right, $P=0.013$ ) and $54 \%$ (left, $P=0.019$ ), respectively. None of the other regions examined showed statistically significant differences in DAAO expression. This post-mortem study demonstrated increased gene expression of DAAO in the left and right hippocampus of schizophrenia patients. This increased expression could be responsible for a decrease in local D-serine levels leading to a NMDA-receptor hypofunction that is hypothesized to play a major role in the pathophysiology of schizophrenia. However, our study group was small and results should be verified using larger samples.

Keywords DAAO - Gene expression - Schizophrenia . In situ hybridization · Hippocampus

\section{Introduction}

Schizophrenia is a complex neurodevelopmental disorder (Weinberger 1987; Lewis and Levitt 2002), in which susceptibility genes are assumed to play a specific role in the pathophysiology of the disease via abnormal synaptic connectivity (Harrison 1999). Genome wide scanning and mapping of regions associated with risk for schizophrenia 
led to the detection of several hypothetical susceptibility genes, including D-amino acid oxidase (DAAO) (Chumakov et al. 2002; Schumacher et al. 2004) in addition to a number of established risk genes. These genes encode proteins involved in processes beginning with brain development to the maintenance of glutamatergic transmission in the adult brain. DAAO is involved in the $N$-methyl-D-aspartate receptor (NMDAR) hypofunction that is hypothesized to play a major role in the pathophysiology of schizophrenia (Coyle 1996). D-Serine, an allosteric activator of the NMDA-type glutamate receptor (NMDAR) in the brain (Schell et al. 1995), is degraded by DAAO. Accordingly, increased DAAO levels might lead to NMDAR dysfunction via decreased serine levels (Kapoor et al. 2006; Bendikov et al. 2007). DAAO itself is a peroxisomal homodimeric flavoenzyme showing the characteristics of the dehydrogenase-oxidase class of flavoproteins with a low kinetic efficiency (Molla et al. 2006). DAAO catalyzes the oxidative deamination of D-amino acids, with the exception of D-aspartate and D-glutamate, which are oxidized by D-aspartate oxidase (DASPO) (Sacchi et al. 2002). Endogenous D-serine is synthesized from L-serine by serine racemase (Wolosker et al. 1999), and is degraded by DAAO, which specifically oxidizes D-amino acids (Horiike et al. 1994; Schell et al. 1995).

The DAAO risk gene has been shown to be associated with schizophrenia (Chumakov et al. 2002; Liu et al. 2004; Schumacher et al. 2004; Corvin et al. 2007; Wood et al. 2007). While the influence of a single risk gene is considered rather small, the coherent influence of multiple susceptibility genes is said to contribute significantly to the risk of developing schizophrenia in either an epistatic or a polygenic mode (Harrison and Weinberger 2005). Li and He (2007) performed a meta-analysis combining all casecontrol and family-based association studies published until October 2005 that involve 16 polymorphisms, including those assessing the genes of D-amino acid oxidase (DAAO) activator (DAOA or G72; located on chromosome 13q32-34) and DAAO (located on chromosome 12q24). Although previous studies have reported strong associations in allelic, genotypic or haplotypic analyses, the results of the presented meta-analysis provided only weak evidence for an association between DAOA/DAAO genes and schizophrenia. Another meta-analysis on DAOA by Detera-Wadleigh and McMahon (2006) presented highly significant evidence of an association between nucleotide variations in the DAOA/DAAO region and schizophrenia. It is interesting to note that the alleles and haplotypes were not identical across the studies-some of them were located $50 \mathrm{~kb}$ telomeric of DAOA (DeteraWadleigh and McMahon 2006). However, there were no real genotypes available, which prevented comparison of haplotype frequencies. Association tests with DAAO, made by Goldberg et al. (2006) were consistently non-significant. They performed two family-based association studies of various single nucleotide polymorphisms in the gene for DAAO. The latest meta-analysis was carried out by Shi et al. (2008) and combined 18 associating studies conducted before April 2007 involving 15 single nucleotide polymorphisms. Of these, two showed an association with schizophrenia in Asians while one was found to be associated with the disorder in Europeans.

While no single marker showed evidence of an overall association with bipolar disorder (Schumacher et al. 2004) several authors hypothesized that DAOA and DAAO might also contribute to bipolar affective disorder, because linkage findings in the chromosomal regions of DAOA and DAAO had similarly been discovered for bipolar disorder (Dawson et al. 1995; Jones and Tarrant 1999; Kelsoe et al. 2001). Additionally, the psychopathological characteristics shared by both schizophrenia and bipolar disorder, leading to the assumption of a commonly shared etiology, also underscore this hypothesis.

In order to emphasize the linkage between DAAO and schizophrenia in a severely affected subpopulation of schizophrenia patients, we investigated gene expression of DAAO in several human brain regions [granular frontal cortex (BA9), middle frontal cortex (BA46), superior temporal cortex (BA22), the entorhinal cortex (BA28), sensoric cortex (BA1-3), the hippocampus (CA4) and the mediodorsal nucleus of the thalamus] by in situ-hybridization. We determined mRNA levels in the right and left hemisphere of schizophrenia patients versus healthy subjects, respectively. So far, it is known that DAAO-mRNA is localized in astrocytes (Yang et al. 2005). Due to the cell specific expression of DAAO in varying cell populations, we chose to analyze gray and white matter in BA9, BA46, BA22, BA28 and BA1-3 separately. We hypothesized a differential expression of DAAO in key regions of schizophrenia pathophysiology, namely the hippocampus CA4. Schizophrenia is not a uniform disease. Instead, it could best be characterized as a syndrome with the different courses of the disease being associated with different neurobiological backgrounds, i.e. first episode versus patients with a chronic course of the disease. Accordingly, we tried to measure DAAO gene expression in the brains of a severely affected subgroup whose patients were thought to have had a similar course of schizophrenia.

\section{Materials and methods}

Human post-mortem tissue

We collected post-mortem brain samples from patients with DSM-IV residual schizophrenia $(n=10)$ and 
elderly comparison subjects $(n=13)$ who had been diagnosed using the DSM-IV checklist of the American Psychiatric Association (APA). Due to incomplete collection of the hippocampus, number of investigated cases ranged from 8 (right hemisphere) up to 10 (left hemisphere) in schizophrenia patients and 10 (right hemisphere) up to 13 (left hemisphere) in healthy probands. All schizophrenia patients had been long-term inpatients at the State Mental Hospital Wiesloch, Germany and had been diagnosed ante-mortem according to DSM IV criteria (American PA, 1994). After assessing patients' history of antipsychotic treatment by examining their medical charts, we then calculated the last dose as well as the cumulative dose during the last 10 years of antipsychotic medication in chlorpromazine equivalents (CPE) through the algorithm developed by Jahn and Mussgay (1989). Table 1 outlines the demographic variables. Controls were collected at the Institutes of Neuropathology, of the Universities of Heidelberg and Bonn and the respective clinical records obtained from their relatives and general practitioners. All assessments and post-mortem evaluations and procedures had been approved by the Ethics Committees of the Faculties of Medicine of Heidelberg and Bonn Universities, Germany.
All patients and controls underwent thorough neuropathologic characterization in order to rule out associated neurovascular or neurodegenerative disorders, such as Alzheimer's disease and multi-infarct dementia (Braak and Braak 1991; Braak et al. 2006). The staging according to Braak was 2 or less for all subjects. Patients and normal comparison subjects had no history of alcohol, drug abuse, or severe physical illness as for example carcinoma. Normal comparison subjects had no history of psychiatric disorders. All patients had been receiving long-term antipsychotic medication before death, such as clozapine $(n=3)$, zotepine $(n=1)$, olanzapine $(n=2)$, flupenthixole $(n=1)$, haloperidol $(n=3)$, perphenazine $(n=1)$, pipamperone $(n=1)$, promethazine $(n=1)$, zuclopenthixole $(n=1)$, perazine $(n=1)$, prothipendyl $(n=1)$.

Post-mortem brains were dissected at the midline of the hemispheres. Tissue blocks were prepared from the granular frontal cortex (BA9), the middle frontal cortex (BA46), the superior temporal cortex (BA22), the entorhinal cortex (BA28), the sensoric cortex (BA1-3), the hippocampus cornu ammonis 4 (CA4), and the mediodorsal nucleus of the thalamus from the right and left hemisphere. Blocks were immediately snap-frozen in liquid nitrogencooled isopentane and stored at $-80^{\circ} \mathrm{C}$. From these, $10 \mu \mathrm{m}$

Table 1 Characteristics of post-mortem samples from patients with schizophrenia and normal comparison subjects

\begin{tabular}{|c|c|c|c|c|c|}
\hline \multirow{2}{*}{$\begin{array}{l}\text { Characteristic } \\
\\
\begin{array}{l}\text { Subjects gender } \\
(N)\end{array}\end{array}$} & \multirow{2}{*}{$\begin{array}{l}\text { Tissue from } \\
\text { patients with } \\
\text { schizophrenia } \\
(n=10) \\
10\end{array}$} & \multicolumn{2}{|c|}{$\begin{array}{l}\text { Tissue from } \\
\text { normal patient } \\
\text { subjects } \\
(n=13)\end{array}$} & & \\
\hline & & \multicolumn{2}{|l|}{13} & & \\
\hline Male & 5 & \multicolumn{2}{|l|}{11} & & \\
\hline \multirow[t]{2}{*}{ Female } & 5 & 2 & & & \\
\hline & & Mean & SD & Mean & SD \\
\hline \multicolumn{2}{|c|}{ Age at death (years) } & 69.10 & 14.40 & 64.54 & 13.58 \\
\hline \multicolumn{2}{|c|}{ Postmortem interval (h) } & 21.00 & 10.66 & 23.85 & 23.12 \\
\hline \multicolumn{2}{|l|}{$\mathrm{pH}$} & 6.42 & 0.35 & 6.65 & 0.37 \\
\hline \multicolumn{2}{|c|}{ Age at onset (years) } & 24.60 & 7.36 & & \\
\hline \multicolumn{2}{|c|}{ Duration of disease (years) } & 43.20 & 11.57 & & \\
\hline \multicolumn{2}{|c|}{ Duration of hospitalization (years) } & 25.10 & 15.32 & & \\
\hline \multicolumn{2}{|c|}{ Duration of antipsychotic medication (years) } & 35.00 & 9.72 & & \\
\hline \multicolumn{2}{|c|}{$\begin{array}{l}\text { Last dose of antipsychotic medication in } \\
\text { chlorpromazine equivalents (CPE in } \mathrm{g} \text { ) }\end{array}$} & 686.26 & 787.36 & & \\
\hline \multicolumn{2}{|c|}{$\begin{array}{l}\text { Cumulative dose (last } 10 \text { years) of antipsychotic } \\
\text { medication in chlorpromazine equivalents (CPE in } \mathrm{kg} \text { ) }\end{array}$} & 4.36 & 3.19 & & \\
\hline
\end{tabular}

There were no statistically significant differences between age at time of death, post-mortem interval (PMI) and brain pH. Schizophrenia patients were characterized by duration of disease, duration of medication and medication (last dose) in chlorpromazine equivalents (CPE), as well as cumulative dose over the last ten years in $\mathrm{CPE}$ 
sections were cut and were collected on coated slides. All material was coded and experiments were carried out by researchers who were blind to diagnosis.

In situ-hybridization

In situ-hybridization (Zink et al. 2005) was performed on two sections of each brain region with ${ }^{35} \mathrm{~S}$-UTP-labeled cRNA-probes of the DAAO gene. RNA from human cerebral cortex (RNeasy, Qiagen, Hilden, Germany) was reverse transcribed with the reverse transcriptase Superscript II (Gibco Life-Technologies, Karlsruhe, Germany) and the oligo-dT-Primers (Perkin-Elmer, Wellesley, USA). After PCR-amplification (Promega, Mannheim, Germany) with specific primers derived from DAAO (bases 251-710 in Genbank NM 001917) the amplicons were subcloned into gGEM-T vector (Promega, Mannheim, Germany). Correct amplification and orientation were checked by commercial sequencing (MWG, Ebersberg, Germany). Linearized plasmids were transcribed in vitro with Sp6 or T7-RNA-polymerase (MBIFermentas, St Leon Roth, Germany). Efficiency of incorporation of radioactively labeled $\left[{ }^{35} \mathrm{~S}\right]$-UTP was measured and hybridizations with antisense- and senseprobes using concentration of $10^{7} \mathrm{cpm} / \mathrm{ml}$ were carried out under high stringency conditions $\left(55^{\circ} \mathrm{C}, 50 \%\right.$ formamide) for $16 \mathrm{~h}$. Hybridizations with sense-probes were intended as negative controls for specificity. After several washing steps including RNAse A-digestion, slices were dehydrated and were exposed to X-ray films (Biomax MR1 $18 \times 24 \mathrm{~cm}$ ) for 2-6 days.

Image analysis

Autoradiographic films (see representative examples of the hippocampus in Fig. 1) were analyzed with a video camera (Sony XC ST 70) and the AIS software (Applied Information Systems, Chapel Hill, USA). Non-specific signals were assessed separately for each section in the white matter separating hippocampal CA4 and cerebral cortex. These readings were subtracted from gray values in the regions of interest (total binding) resulting in a semiquantitative determination of mRNA-abundance. Gray value images of the co-exposed ${ }^{14} \mathrm{C}$-calibration standards (Amersham, Buckinghamshire, UK) were used to compute a calibration curve by non-linear least squares fitting, which defined the relationship between gray values and concentration of radioactivity.

We measured DAAO specific bindings in the cortical brain regions in both gray and white matter. In the hippocampus, the region of interest was the CA4 region. In the thalamus, we investigated the mediodorsal nucleus. Both regions were selected due to their impact in the

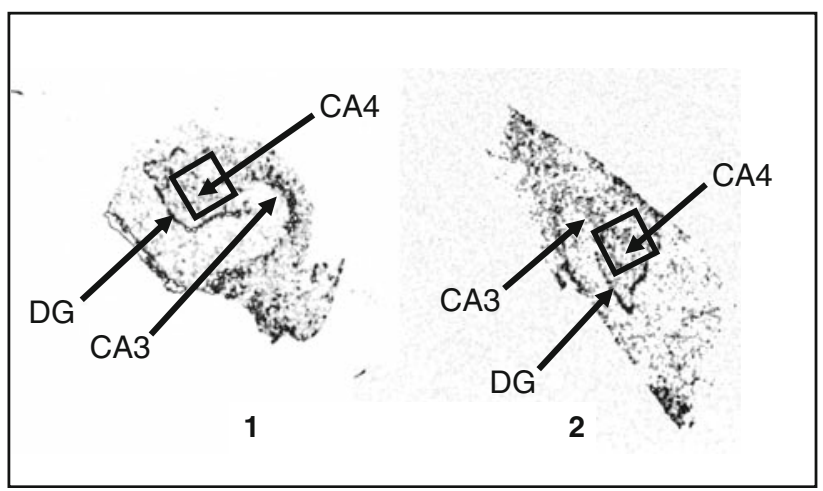

Fig. 1 Gene expression of DAAO in the hippocampus expressed as $\mathrm{Bq} / \mathrm{g}$ brain tissue in the gray matter of the right and left hemisphere. Compared to the control group, we found a statistically significant increase in the expression of $46 \%(P=0.013)$ in the right and of $54 \%$ $(P=0.019)$ in the left hemisphere of the hippocampal CA4 of schizophrenic patients

pathophysiology of schizophrenia (Schmitt et al. 2009; Carlsson et al. 1999).

\section{Statistical analysis}

Statistical analyses were performed with SPSS 15. All tests were two-tailed. The level of significance was defined as $P<0.05$. Distributions for all dependent variables were examined in both groups using histograms and the Kolmogorov-Smirnov test on normality. Due to our small sample size, the power for the Kolmogorov-Smirnov test was not very high. Nonetheless, our results suggest a normal distribution of the data and analysis by parametric tests.

In all regions analyzed, we first performed oneway analyses of variance (ANOVA) with diagnostic group as independent factor. Additionally, we assessed correlations between the dependent and intervening variables age, PMI, brain $\mathrm{pH}$, disease duration, dose, and duration of medication using Spearmen rank correlation coefficients, as some of the intervening variables like PMI and medication dose deviated significantly from normal distribution. These correlations were computed separately for schizophrenia patients and-if present-for controls. In all regions, oneway ANOVA with factor gender was calculated to analyze if specific bindings differed between male and female subjects. As in these initial analyses, age and PMI showed a significant influence on specific bindings in the hippocampal region, we performed analyses of covariance (ANCOVA) with diagnostic group as independent factor and age and PMI as covariates.

This is an explorative study aimed at finding variables that may show differences in the expression of DAAOmRNA between schizophrenia patients and control subjects. If a Bonferroni adjustment of the error probability of 
first kind for the number of statistical tests was applied, no significant differences between schizophrenia patients and controls would remain. However, one must keep in mind that adjustment of the error probability would decrease the power of the test to such an extent that the power of detecting existing mean differences would be very low. Thus, the present results are presented without error probability correction. Due to our explorative study design and the problems of multiple testing, these findings offer no conclusive evidence for a causal relationship. An independent larger sample has to be analyzed in an effort to confirm the positive findings of this study.

\section{Results}

Descriptives for specific bindings in the analyzed regions are shown in Table 2. In the present study, the hippocampal CA4 of schizophrenia patients revealed a significant increased expression of DAAO-mRNA in both hemispheres. Compared to the control group, we noted a $46 \%$ increase in expression $(F=6.5 ; d f=1,10 ; P=0.029)$ in the right CA4 of schizophrenia patients (Fig. 1) and an increase of $54 \%$ of DAAO-mRNA in the left CA4 $(F=5.8 ; d f=1,9$; $P=0.039$ ) in ANOVA (Fig. 2). Schizophrenia patients did not differ from controls in terms of age $(F=0.6 ; d f=1,21$; $P=0.45), \quad \mathrm{pH} \quad(F=0.5 ; \quad d f=1,20, \quad P=0.68), \quad$ PMI $(F=0.1 ; d f=1,21 ; P=0.72)$ or gender $\left(\chi^{2}=3.20\right.$; $d f=1 ; P=0.074)$.

In all other regions assessed [the granular frontal cortex (BA9), the middle frontal cortex (BA46), the superior temporal cortex (BA22), the entorhinal cortex (BA28), the sensoric cortex (BA1-3), and the mediodorsal nucleus of the thalamus], we saw no statistically significant differences in the expression of DAAO. Overall, in controls, the mediodorsal nucleus of the thalamus and CA4 of the hippocampus showed the least expression, while the cortical regions BA46 and 28 showed the highest level of expression (Table 2).

In schizophrenic patients, we noted significant correlations between specific bindings and age (rho $=0.94$, $P=0.005)$ in the left hippocampus along with significant correlations between specific bindings and PMI (rho $=0.90, P=0.037$ ) in the right hippocampus. Specific binding of DAAO in the hippocampus did not show any significant influences of gender or brain $\mathrm{pH}$.

From analysis of covariance (ANCOVA, factor diagnosis, covariates age, PMI) intending to adjust the analysis on diagnostic effects for these intervening variables, the noted increase in DAAO-mRNA expression in schizophrenic patients was still significant in both the right $(F=11.1, d f=1,8, P=0.013)$ and the left $(F=9.3$, $d f=1,7, P=0.019$ ) hippocampal CA4 (Fig. 2).

Furthermore, schizophrenic patients showed significant correlations between specific bindings and disease duration (rho $=0.83, P=0.042$ ) as well as duration of medication (rho $=0.83, P=0.042$ ) in the left CA4. However, correlations of last dose and cumulative dose (last 10 years) with DAAO expression levels were not significant.

\section{Discussion}

To the best of our knowledge, the present post-mortem investigation is the first study showing increased gene

Table 2 Descriptive Statistics for specific bindings (mean \pm standard deviation) expressed in Bq/g brain tissue in the analyzed brain regions in schizophrenic patients and controls

\begin{tabular}{|c|c|c|c|c|}
\hline \multirow[t]{2}{*}{ Region } & \multicolumn{2}{|c|}{ Left hemisphere } & \multicolumn{2}{|c|}{ Right hemisphere } \\
\hline & $\begin{array}{l}\text { Control } \\
\text { Mean } \pm \text { SD }\end{array}$ & $\begin{array}{l}\text { Schizophrenia } \\
\text { Mean } \pm \text { SD }\end{array}$ & $\begin{array}{l}\text { Control } \\
\text { Mean } \pm \text { SD }\end{array}$ & $\begin{array}{l}\text { Schizophrenia } \\
\text { Mean } \pm \text { SD }\end{array}$ \\
\hline BA9 granular frontal cortex (white matter) & $579 \pm 215$ & $595 \pm 174$ & $837 \pm 85$ & $594 \pm 252$ \\
\hline BA9 granular frontal cortex (gray matter) & $452 \pm 190$ & $428 \pm 145$ & $494 \pm 172$ & $437 \pm 181$ \\
\hline BA46 middle frontal cortex (white matter) & $692 \pm 0$ & $745 \pm 138$ & $717 \pm 0$ & $691 \pm 230$ \\
\hline BA46 middle frontal cortex (gray matter) & $466 \pm 159$ & $573 \pm 125$ & $572 \pm 207$ & $549 \pm 191$ \\
\hline BA22 superior temporal cortex (white matter) & $527 \pm 0$ & $523 \pm 63$ & $696 \pm 259$ & $475 \pm 72$ \\
\hline BA22 superior temporal cortex (gray matter) & $418 \pm 152$ & $644 \pm 297$ & $551 \pm 192$ & $549 \pm 199$ \\
\hline BA1-3 sensoric cortex (white matter) & $471 \pm 187$ & $597 \pm 155$ & $621 \pm 280$ & $549 \pm 224$ \\
\hline BA1-3 sensoric cortex (gray matter) & $410 \pm 179$ & $491 \pm 234$ & $476 \pm 191$ & $438 \pm 185$ \\
\hline Hippocampus (CA4) & $401 \pm 42$ & $619 \pm 197 *$ & $353 \pm 84$ & $515 \pm 137^{*}$ \\
\hline BA28 entorhinal cortex (white matter) & $624 \pm 281$ & $724 \pm 206$ & $740 \pm 302$ & $499 \pm 379$ \\
\hline BA28 entorhinal cortex (gray matter) & $559 \pm 234$ & $582 \pm 248$ & $556 \pm 243$ & $550 \pm 265$ \\
\hline Thalamus (mediodorsal nucleus) & $424 \pm 115$ & $450 \pm 156$ & $369 \pm 84$ & $363 \pm 157$ \\
\hline
\end{tabular}

Significant differences have been detected in hippocampal CA4 $(* P<0.05)$ 
Fig. 2 Exemplary X-ray film analysis obtained from the computer program AIS (Analytical Imaging Station ${ }^{\circledR}$ from Interfocus). The intensity of the ${ }^{35}[\mathrm{~S}]$-isotope was measured in $\mathrm{Bq} / \mathrm{g}$ brain tissue. On the slides ( 1 left hemisphere, 2 right hemisphere) we marked our region of interest CA4 (rectangle) and the subregions CA3 and the dentate gyrus $(D G)$ expression of DAAO in the hippocamus

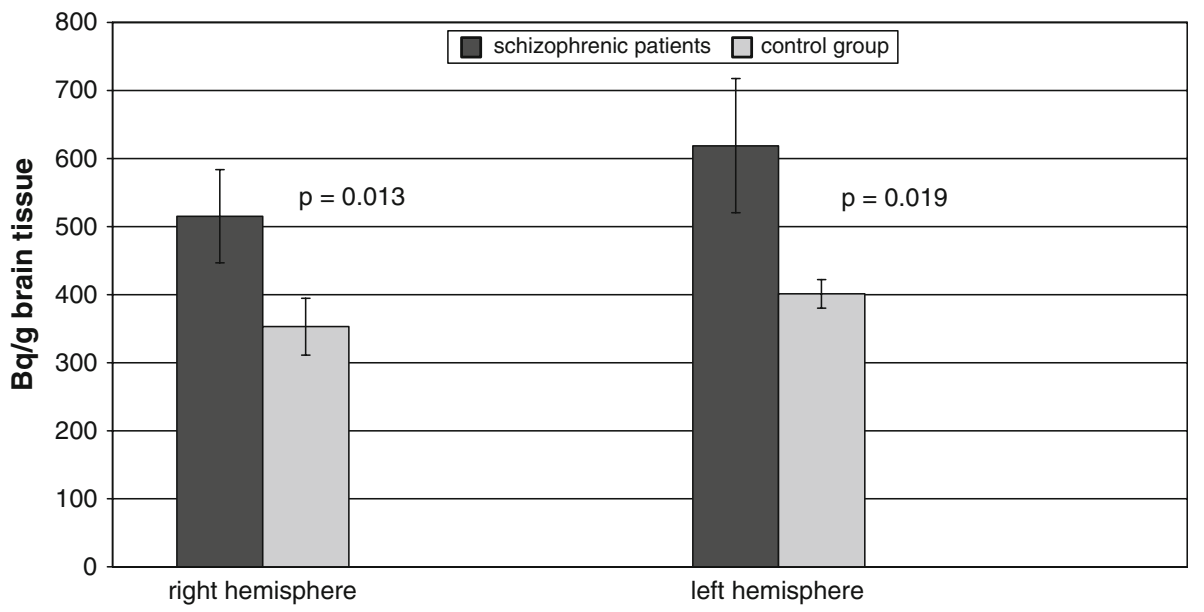

expression of DAAO in the left and right hippocampus (CA4) of schizophrenia patients compared to healthy subjects. Concerning mRNA levels, Kapoor et al. (2006) determined the presence of DAAO in human brain tissues from schizophrenic and normal individuals via RT-PCR. They found the relative expression of DAAO-mRNA to be higher in the cerebellum than in the parietal cortex and cerebellar mRNA levels that were significantly higher in schizophrenia patients versus controls. Additionally, they explored DAAO activity in both regions by a colorimetric method (Kapoor et al. 2006) showing that DAAO activity was significantly higher in the cerebellum of schizophrenic patients and undetectable in the human parietal cortex. Bendikov et al. (2007) monitored DAAO protein levels in post-mortem frontal cortex and hippocampus by Westernblot analysis, finding no significant differences in schizophrenia patients. They did note, however, that hippocampal DAAO levels correlated significantly with the duration of disease. This is in line with our findings of a significant correlation between DAAO expression and the duration of disease as well as duration of medication in the left hippocampus. As age, disease duration, and duration of medication are dependent, the respective correlations may be related to each other.

It must be kept in mind that the present study only measured DAAO expression in a chronic subgroup of schizophrenia patients, as we wanted to assess effects in the most severely affected subgroup in the schizophrenia syndrome. If we had included patients with shorter disease durations, it is possible that our findings would not persist. Madeira et al. (2008) demonstrated an increase in DAAO activity in the parietal cortex of schizophrenic patients. They also found that the group of individuals with a history of antipsychotic drug use showed significantly higher DAAO activity when compared to individuals with no history. The first group included all schizophrenic patients and a subset of patients suffering bipolar disorder. Both psychotic disorders share many features and several authors argue that the illnesses could represent a continuum of symptoms. However, they did not investigate patients of the same diagnostic group without antipsychotics and with antipsychotic treatment, rendering comparisons of treatment effects difficult.

While Verrall et al. (2006) discovered a statistically significant increase in the expression of DAAO-mRNA in the cerebellum of schizophrenic patients, but their immunohistochemical studies only showed a trend of the protein level in this direction. In our study, we did not investigate the cerebellum. However, in line with our findings, they reported no differential expression of DAAO in the DLPFC. In this region, Verrall et al. also found a statistically significant increase in the expression of the serine racemase, an enzyme of the synthesis of D-serine, further supporting other disturbances of the D-serine pathway in schizophrenia.

The increased expression of DAAO in both sides of the hippocampus could be responsible for a decrease in hippocampal D-serine (Bendikov et al. 2007; Hashimoto et al. 2003, Hashimoto et al. 2005), leading to a NMDA receptor hypofunction that is thought to occur in schizophrenia (Coyle 1996; Chumakov et al. 2002). By detecting statistically significant increases in DAAO expression values only in the hippocampus and not in any other brain region, alterations of DAAO expression in schizophrenia seem to be region-specific.

In our study, we investigated Cornu ammonis (CA4) of the left and right hippocampus. Previously, we reported decreased numbers of oligodendrocytes in the left and right hippocampus (CA4) of schizophrenic patients, showing the impact of this region in the pathophysiology of schizophrenia (Schmitt et al. 2009). Among hippocampal subfields, CA4 is the deep polymorph layer of the dentate 
gyrus and receives collateral mossy fibers from the granulate cells (Amaral and Lavanex 2007). CA4 is among the regions hypothesized to be strongly involved in disturbances of connectivity in schizophrenia (Harrison and Eastwood 2001).

The hippocampus plays an important role in memory consolidation as well as the transfer of memory contents from short-term to long-term memory, and disturbances of verbal memory have been detected in schizophrenia (Heckers and Konradi 2002). Structural magnetic resonance imaging and post-mortem studies in schizophrenia have shown volume loss in the medial temporal region, especially in the hippocampus, as one of the most consistent structural abnormalities (Heckers 2001).

Additionally, post-mortem studies have shown volume loss in hippocampal subregions in schizophrenia, which may be related to positive symptoms (Bogerts et al. 1990, 1993; Bogerts 1997).

A new approach regarding pharmacological treatment of schizophrenia is an in vitro and in vivo trial with a selective DAAO inhibitor (Adage et al. 2008). A pharmaceutical product based on selective DAAO inhibitors was not only able to increase D-serine fraction in rat cortex and midbrain, but also had a normalizing effect on phencyclidine (PCP)-induced prepulse inhibition and hyperlocomotion in mice. The mechanism of action of this inhibitor is the increase of D-serine levels by preventing the oxidation of D-serine via DAAO. D-serine is an endogenous full agonist at the glycine site of the NMDA-receptor. By increasing the bioavailability of D-serine, one should consequently achieve enhanced NMDA neurotransmission leading to potential anti-psychotic activities. This new therapeutic approach shows the importance of better insight into the DAAO/D-serine/glycine equilibrium, which should be investigated in large studies to assess and provide proof for new therapy options through modification of the respective equilibrium.

In summary, we detected increased gene expression of DAAO in the left and right hippocampus (CA4) of schizophrenia patients compared to a healthy comparison group. These alterations may be related to the pathophysiology of schizophrenia, such as the hypoglutamatergic state with NMDA receptor hypofunction, the GABAergic deficit as well as migrational and myelination disturbances. However, our study also entails some limitations. First, our finding of increased bindings in the left and right hippocampus might not hold up, if a more stringent statistical analysis adjusting of the first kind error probability for the number of investigated regions was applied. Keeping this in mind, the results of this explorative study should be interpreted with caution, until they are confirmed on a larger independent sample. Especially, in the right hippocampus, we investigated only a low number of cases.
In this post-mortem study, all patients had been treated with typical or atypical neuroleptics over decades, so that one might speculate that antipsychotic treatment itself may have influenced our results. However, as there was no correlation with the cumulative or last dose of antipsychotics in CPE and DAAO expression, we suggest no strong influence of antipsychotic treatment on our results. To gain additional insight animal studies investigating the influence of neuroleptics on DAAO expression are warranted. Furthermore, since many findings in post-mortem tissue are not specific for schizophrenia, psychiatric patients with other diagnoses such as bipolar disorder should be investigated to show diseasespecific effects on DAAO expression. Moreover, since we did not investigate protein levels of DAAO isoforms, it is not entirely clear, if changes in the level of the mRNA transcript also reflect changes in protein levels, which again limits our conclusions. Further, post-mortem studies should investigate DAAO and D-serine activity as well as expression of NMDA receptor subunits in the hippocampus to determine whether the change in mRNA results in a functional outcome. Additional investigations are required to clarify the influence of the DAAO gene on the expression of mRNA and protein level, and to identify at-risk polymorphisms within the DAAO and DAOA gene associated with a risk for schizophrenia.

Acknowledgments This study was supported by the European Commission under the Sixth Framework Programme (BrainNet Europe II, LSHM-CT-2004-503039). The paper reflects only the authors' views and the Community is not liable for any use that may be made of it. The authors would like to thank Udo Rueb for Braak staging and Mrs. Waltraud VanSyckel for her valuable assistance with language revision.

Open Access This article is distributed under the terms of the Creative Commons Attribution Noncommercial License which permits any noncommercial use, distribution, and reproduction in any medium, provided the original author(s) and source are credited.

\section{References}

Adage T, Trillat AC, Quattropani A, Perrin D, Cavarec L, Shaw J, Guerassimenko O, Giachetti C, Greco B, Chumakov I, Halazy S, Roach A, Zaratin P (2008) In vitro and in vivo pharmacological profile of AS057278, a selective D-amino acid oxidase inhibitor with potential anti-psychotic properties. Eur Neuropsychopharmacol 18(3):200-214

Amaral D, Lavanex P (2007) Hippocampal neuroanatomy. In: Andersen P, Morris R, Amaral D, Bliss T, O'Keefe J (eds) The hippocampal book. Oxford University Press, NY, pp 37-114

American PA (1994) Diagnostic and statistical manual of mental disorders, 4th edn. American Psychiatric Association, Washington

Bendikov I, Nadri C, Amar S, Panizzutti R, DeMiranda J, Wolosker H, Agam G (2007) A CSF and postmortem brain study of D-serine metabolic parameters in schizophrenia. Schizophr Res 90:41-51

Bogerts B (1997) The temporolymbic system theory of positive schizophrenic symptoms. Schizophr Bull 23:423-435 
Bogerts B, Falkai P, Haupts M, Greve B, Ernst S, Tapernon-Franz U, Heinzmann U (1990) Post-mortem volume measurements of limbic system and basal ganglia structures in chronic chizophrenics. Initial results from a new brain collection. Schizophr Res 3:295-301

Bogerts B, Lieberman JA, Ashtari M, Bilder RM, Degreef G, Lerner G, Johns C, Masiar S (1993) Hippocampua-amygdala volumes and psychopathology in chronic schizophrenia. Biol Psychiatry 33:236-246

Braak H, Braak E (1991) Neuropathological staging of Alzheimerrelated changes. Acta Neuropathol 82(4):239-259

Braak H, Alafuzoff I, Arzberger T, Kretzschmar H, Del Tredici K (2006) Staging of Alzheimer disease-associated neurofibrillary pathology using paraffin sections and immunocytochemistry. Acta Neuropathol 112(4):389-404

Carlsson A, Waters N, Carlsson ML (1999) Neurotransmitter interactions in schizophrenia-therapeutic implications. Eur Arch Psychiatry Clin Neurosci 249(Suppl 4):IV37-IV/43

Chumakov I, Blumenfeld M, Guerassimenko O, Cavarec L, Palicio M, Abderrahim H, Bouguelleret L, Barry C, Tanaka H, La Rosa $P$ (2002) Genetic and physiological data implicating the new human gene G72 and the gene for D-amino acid ocidase in schizophrenia. Proc Natl Acad Sci USA 99:13675-13680

Corvin A, Donohoe G, McGhee K, Murphy K, Kenny N, Schwaiger S, Nangle JM, Morris D, Gill M (2007) D-amino acid oxidase (DAO) genotype and mood symptomatology in schizophrenia. Neurosci Lett 426(2):97-100

Coyle JT (1996) The glutamatergic dysfunction hypothesis for schizophrenia. Harv Rev Psychiatry 3(5):241-253

Dawson E, Parfitt E, Roberts Q, Daniels J, Lim L, Sham P, Nothen M, Propping P, Lanczik M, Maier W (1995) Linkage studies of bipolar disorder in the region of the Darier's disease gene on chromosome 12q23-24.1. Am J Med Genet 60:94-102

Detera-Wadleigh SD, McMahon FJ (2006) G72/G30 in Schizophrenia and bipolar disorder: review and meta-analysis. Biol Psychiatry 60(2):106-114

Goldberg TE, Straub RE, Callicott JH, Hariri A, Mattay VS, Bigelow L, Coppola R, Egan MF, Weinberger DR (2006) The G72/G30 gene complex and cognitive abnormalities in schizophrenia. Neuropsychopharmacology 31:2022-2032

Harrison PJ (1999) The neuropathology of schizophrenia: a critical review of the data and their interpretation. Brain 122:593-624

Harrison PJ, Eastwood SL (2001) Neuropathological studies of synaptic connectivity in the hippocampal formation in schizophrenia. Hippocampus 11:508-519

Harrison PJ, Weinberger DR (2005) Schizophrenia genes, gene expression, and neuropathology: on the matter of their convergence. Mol Psychiatry 10(1):40-68

Hashimoto K, Fukushima T, Shimizu E, Komatsu N, Watanabe H, Shinoda N, Nakazato M, Kumakiri C, Okada S, Hasegawa H, Imai K, Iyo M (2003) Decreased serum levels of D-serine in patients with schizophrenia: evidence in support of the $N$-methyl-D-aspartate receptor hypofunction hypothesis of schizophrenia. Arch Gen Psychiatry 60:572-576

Hashimoto K, Engberg G, Shimizu E, Nordin C, Lindstrom LH, Iyo M (2005) Reduced D-serine to total serine ratio in the cerebrospinal fluid of drug naive schizophrenic patients. Prog Neuro psychopharmacol Biol Psychiatry 29:767-769

Heckers S (2001) Neuroimaging studies of the hippocampus in schizophrenia. Hippocampus 11:520-528

Heckers S, Konradi C (2002) Hippocampal neurons in schizophrenia. J Neural Transm 109:891-905

Horiike K, Tojo H, Arai R, Nozaki M, Maeda T (1994) D-Amino-acid oxidase is confined to the lower brain stem and cerebellum in rat brain: regional differentiation of astrocytes. Brain Res 652:297303
Jahn T, Mussgay L (1989) Die statistische Kontrolle möglicher Medikamenteneinflüsse in experimentalpsychologischen Schizophreniestudien: ein Vorschlag zur Berechnung von Chlorpromazinäquivalenten. Z Klin Psychol 18:257-267

Jones PB, Tarrant CJ (1999) Specificity of developmental precursors to schizophrenia and affective disorders. Schizophr Res 39(2):121-125

Kapoor R, Lim KS, Cheng A, Garrick T, Kapoor V (2006) Preliminary evidence for a link between schizophrenia and NMDA-glycine site receptor ligand metabolic enzymes, D-amino acid oxidase (DAAO) and kynurenine aminotransferase-1 (KAT-1). Brain Res 1106(1):205-210

Kelsoe JR, Spence MA, Loetscher E, Foguet M, Sadovnicki AD, Remick RA, Flodman P, Khristich J, Mroczkowski-Parker Z, Brown JL, Masser D, Ungerleider S, Rapaport MH, Wishart WL, Luebbert H (2001) A genome survey indicates a possible susceptibility locus for bipolar disorder on chromosome 22. Proc Natl Acad Sci USA 98(2):585-590

Lewis DA, Levitt P (2002) Schizophrenia as a disorder of neurodevelopment. Annu Rev Neurosci 25:409-432

Li D, He L (2007) G72/G30 genes and schizophrenia: a systematic meta-analysis of association studies. Genetics 175:917-922

Liu X, Hea G, Wanga X, Chena Q, Qiana X, Lina W, Lia D, Guc N, Fengc G, Heb L (2004) Association of DAAO with schizophrenia in the Chinese population. Neurosci Lett 369:228-233

Madeira C, Freitas ME, Vargas-Lopes C, Wolosker H, Panizzutti R (2008) Increased brain D-amino acid oxidase (DAAO) activity in schizophrenia. Schizophr Res 101(1-3):76-83

Molla G, Sacchi S, Bernasconi M, Pilone MS, Fukui K, Pollegioni L (2006) Characterization of human D-amino acid oxidase. FEBS Lett 580:2358-2364

Sacchi S, Lorenzi S, Molla G, Pilone MS, Rossetti C, Pollegioni L (2002) Engineering the substrate specificity of D-amino-acid oxidase. J Biol Chem 277:27510-27516

Schell MJ, Molliver ME, Snyder SH (1995) D-serine, an endogenous synaptic modulator: localization to astrocytes and glutamatestimulated release. Proc Natl Acad Sci USA 92:3948-3952

Schmitt A, Steyskal C, Bernstein HG, Schneider-Axmann T, Parlapani E, Schaeffer EL, Gattaz WF, Bogerts B, Schmitz C, Falkai P (2009) Stereologic investigation of the posterior part of the hippocampus in schizophrenia. Acta Neuropathol 117:395-407

Schumacher J, Abon Jamra R, Freudenberg J, Becker T, Ohlraun S, otte ACJ, Tullius M, Kovalenko S, Van Den Bogaert A, Maier W, Rietschel M, Propping P, Nöthen MM, Cichon S (2004) Examination of G72 and D-amino-acid oxidase as genetic risk factors for schizophrenia and bipolar affective disorder. Mol Psychiatry 9:203-207

Shi J, Gershon ES, Liu C (2008) Genetic associations with schizophrenia: meta-analyses of 12 candidate genes. Schizophr Res 104(1-3):96-107

Verrall L, Hutchinson L, Harrison P, Burnet P (2006) D-amino acid oxidase and serine racemase expression in the dorso-lateral prefrontal cortex in schizophrenia. Int $\mathbf{J}$ Neuropsychopharmacol 9:143

Weinberger DR (1987) Implications of normal brain development for the pathogenesis of schizophrenia. Arch Gen Psychiatry 44:660 669

Wolosker H, Blackshaw S, Snyder SH (1999) Serine racemase: a glial enzyme synthesizing D-serine to regulate glutamate- $N$-methyl-Daspartate neurotransmission. Proc Natl Acad Sci USA 96:1340913414

Wood LS, Pickering EH, Dechaio BM (2007) Significant support for DAO as a schizophrenia susceptibility locus: examination of five genes putatively associated with schizophrenia. Biol Psychiatry 61(10):1195-1199 
Yang S, Qiao H, Wen L, Zhou W, Zhang Y (2005) D-serine enhances impaired long-term potentiation in CA1 subfield of hippocampal slices from aged senescence-accelerated mouse prone/8. Neurosci Lett 379(1):7-12
Zink M, Rapp S, Gebicke-Haerter P, Henn FA, Thome J (2005) Antidepressants differentially affect expression of complexin I and II RNA in rat hippocampus. Psychopharmacology 181:560 565 